\title{
Enabling Intragenerational third places as New Incubators of Sociability and Placemaking in Times of Transition
}

\author{
Tigran Haas* \\ Associate Professor of Urban Planning and Urban Design at KTH Royal Institute of Technology, KTH Royal Institute of Technology, \\ Stockholm, Sweden
}

*Corresponding author: Dr. Tigran Haas, Associate Professor of Urban Planning and Urban Design at KTH Royal Institute of Technology, and Director of the Centre for the Future of Places (CFP) at KTH, Stockholm, Sweden

\begin{abstract}
One of the most influential place theories, or conceptual frameworks that deal with the framing, activation and management (as well as understanding) of the public realm, for which the coffee shop, bookstore, taverna, bistro, bakery, pub, etc. became a metonym, was the idea of the "Third Place": a term that emerged to describe new social environments that were distinct from both home (the first place) and work (the second place) and which revolved around leisure, consumption and the desire for the social with a lesser emphasis on the community Banerjee Tridib [1], Oldenburg Ray [2]. The full vocabulary that thoughtful public realms, intragenerational and inclusive can offer, as prime public places, is a vivid example of Oldenburg's third place theory (1999) which he centers round a place to which person(s) are drawn into some kind of sanctuary, serenity, relaxation and refuge feeling and atmosphere. This is a place where the community feeling is being developed and nurtured (Figure 1).
\end{abstract}

\section{Introduction}

The main argument is that third places, places where people can gather, relax after work, put aside their differences, concerns of work and home, and just hang out simply for the pleasures of good company and lively conversation, are the heart of (any) community's social vitality and are the grassroots of democracy Oldenburg R [3] (Figure 2). Third places are gathering places and their importance is in nourishing sociability. For these places to work, they need to fully enable a culture of social inclusion, multiculturalism, ethnic diversity and a balance social-mix, instead of becoming very segregated, mono cultural realms. One thing is certain: these places such as coffee houses, community centers, groceries, markets, bazaars, parks, discussion rooms, etc. are of extreme importance for a vibrant life of any neighborhood, town or city. Now on the opposite site of the pendulum, but still making sense of cities complex hybridities and constant transformations, Edward Soja's "third space" presents itself as an extremely useful term (curiously resembling in form, though definitely not meaning, the Oldenburg Third Place). In essence, third spaces are those which overlay real spaces (the first space) and imagined spaces (the second space), both we mentioned above, to produce in something that is open-ended, undefinable, fluid, and endlessly complex (as are, Soja argues, so many contemporary urban spaces in cities). Soja Edward W [4]. Importantly, third spaces are not only physically constructed but socially and virtually constructed (Something that Oldenburg has not envisioned at all) as well: a factor which, above all, infers that they may be differentially constructed. By the way, Soja's theory of the third space builds on Henri Lefebvre's concept of the spatial triad Lefebvre $H$ [5]. Lefebvre's production of space ideas remains contentious but highly relevant for the investigation of city transformation in general and how the planning of urban space can contribute to social injustice in particular University of Minnesota Press. and Harvey D [6]. What Oldenburg describes as "the problem of place" one of the foci and key driving elements his social urban geography work, and is where Soja's concept of third space differs most dramatically; as in third spaces, the key link between participants is not normally their location but shared links that draw people together. 


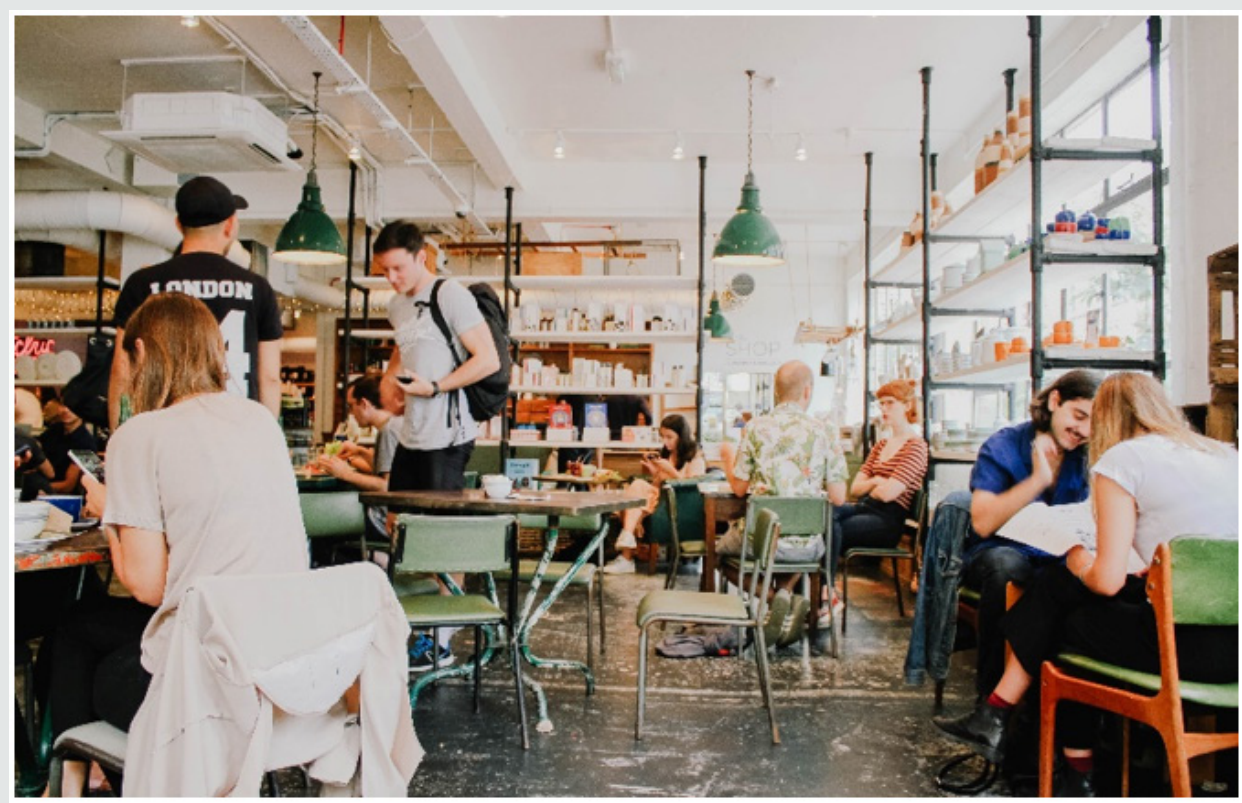

Figure 1: Barber and Parlour Third Place, London, United Kingdom by Toa Heftiba. Reproduced by Permission.

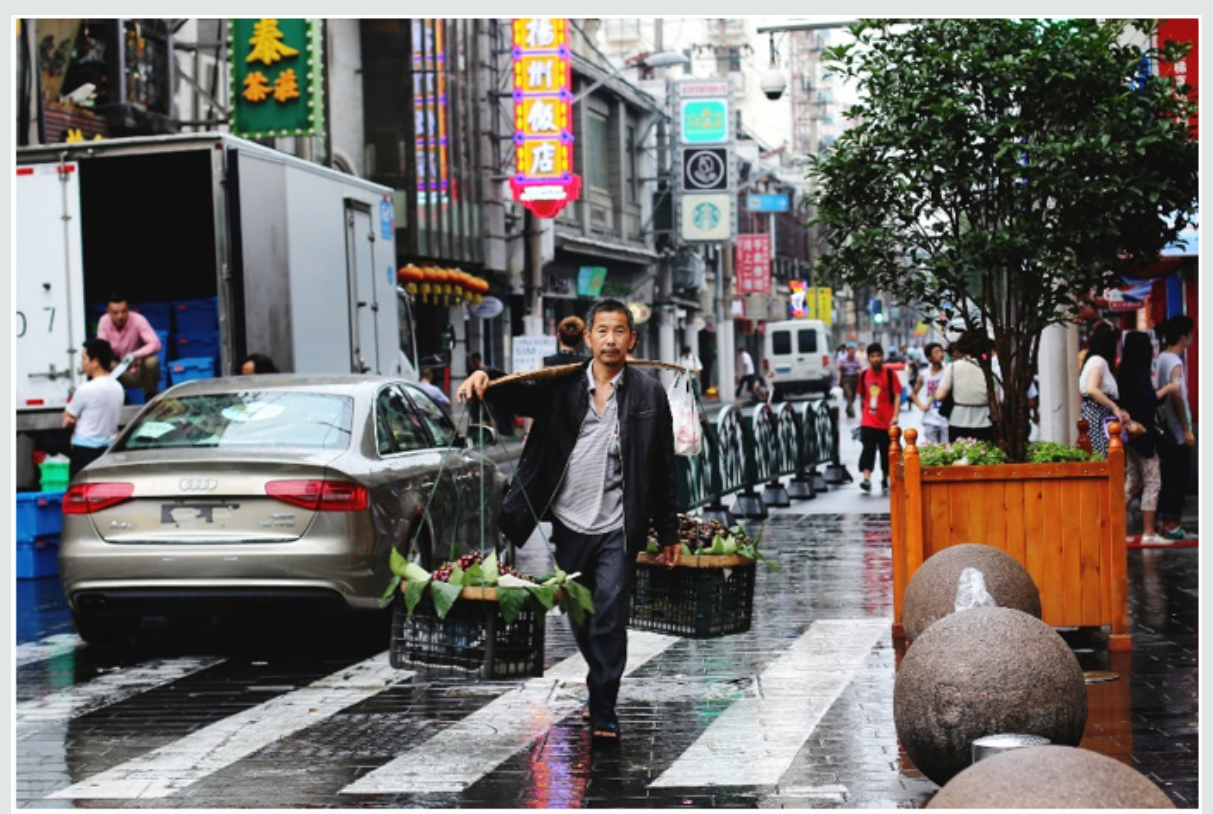

Figure 2: Spaces, Place and People of Shanghai, China, Photo by Christie Kim. Reproduced by Permission.

Communities include things held in common, like government and social structure as well as a common sense of place or location. Main function of the community (local community-gemeinschaft) is to mediate between the individual and society (geselschaft), and that people could relate to their societies through both geographic and non-geographic substructures of communities Hillery G [7]. The third place is an outcry for the return to the fundamental values of a community; some which have been forgotten and erased in today's age of fast changes, superficial values and eradicated places. The popularity of a place where new social networks are built and old maintained can never be or made obsolete. Third places have existed for hundreds of years. They wereplaces that had their appeal and that were symbols and active mediators in community communication. As Oldenburg calls them-social condensersplaces, agoras if you will, where all citizens of the community or a neighborhood meet to develop the place where citizens of a community or neighborhood meet to develop friendships, discuss issues, and interact (socially changes, positive and negative ones alike. A well-functioning public realm with a third place richness can build social capital by enforcing and melding social relations Putnam R, Lewis F [8]. This happens through in-continuo social contact among people in multiple overlapping role relationships Lennard Crowhurst S, Lennard, H [9]. 
These third places are crucial to a community for a number of reasons. They are firstly distinctive informal gathering places, secondly, they make the citizen feel at home, thirdly they nourish relationships and a diversity of human contact, fourthly they help create a sense of place and community and finally they invoke a sense of civic pride Oldenburg R [10]. The key ingredient lies in the fact that they are socially binding, encouraging sociability at the same time and fighting against isolation. They simply make life more joyous, colorful, and they enrich city's economic activity, public life and democracy. The life of third places in coffee shops, cafés, hair salons, restaurants, bakeries, semi-informal meeting places, bazaars, other markets, gardens etc. are in alignment with the argument that these types of places are the facilitators of vibrant and good public life and that in most cases they are in synergy with open public spaces, like squares, bazaars and other markets. [3] points at the essential ingredients for a well-functioning third place: 1 . They must be free or relatively inexpensive to enter and to purchase food and drinks. They must be highly accessible; ideally one should be able to get there by foot from one's home; A number of people can be expected to be there on a daily basis; All people should feel welcome, regardless of their race, gender or religion and it should be easy to get into a conversation. A person who goes there should be able to find both old and new friends each time they visit. Third places are retreats into social spaces from a selfish need with those of like mind. Its where we foster some of our selfesteem, and a great deal of our social capital, that helps us survive and bridge home and work Putnam RD [11].

Freud held that emotional wellbeing depends upon having someone to love and a work to do. Oldenburg argues that we also need a dependable place of refuge where, for a few minutes a day, we can escape the demands of family and work environment Oldenburg $\mathrm{R}$ [10]. Third places in action, where intergenerational spirit exists, can provide possible and viable foundation for: 1) foster a sense of connection between people (of different age, gender, ethnicity, social class, sexual orientation, political or religious beliefs) 2) create temporary and permanent venues where a vibrant exchange of ideas can take place 3) encourage those ideas to lead to real efforts that bring progress to the community 4) offer an enjoyable and long-lasting social and aesthetic environment both for you, elderly and in the middle-for all geographies of age.

Built environment supports the built-up of social capital not just amongst adults, elderly but also between children. Especially for children the concept of the traditional European square offers an important learning environment. Primarily, children learn by repeated observation, imitation and practice in relating to a range of adults in multiple contexts Lennard $\mathrm{H}$ [12]. The disturbing lack of good public spaces in our cities, town and neighborhoods where children are able to gather and play, can have a tremendous impact on urban culture. Lack of these places reinforces the already omnipresent alienation and loss of real sense of place for children, which has to do a lot with the overuse of video, TV and other electronic media (rise of obesity levels due to lack of walking, exercise, etc.). Another problem is lack of walking and the overuse of automobile for transportation of children even on very short distances.

Because children cannot always reach places on their own, they rely upon their parents to transport them everywhere (thus the "soccer mom" phenomenon in American suburbia). The problem is also that children often play in the street and across several open front lawns. It is impossible, however, to define this area as urban space (like a public square) bounded by surrounding houses and trees, when distances between opposite houses are enormous Gehl J [13]. The common mistake is made when parks are being associated with public squares. Parks are designed with specific areas set aside for recreational activities or quiet contemplation. A typical park is an area dominated by grass, trees, water and pathways. Public squares are designed with paved surfaces to accommodate a variety of uses that parks cannot offer, including the relation to the built environment, orientation, legibility and imageability. However, both are needed in order to create livable places and one does not exclude the other. Public places (squares) have also a value to children for play. This becomes very obvious when kids learn to use their imaginations and expand their sense of curiosity in an environment that offers much more than just landscape. It is also a place where children learn how to properly socialize with their equals, to organize themselves, and to resolve disputes. The same could be said of society. Environmental psychology has looked into those aspects where there are clear indications that the opportunity to explore rich, varied public realm environments appears related to cognitive, social, and motor development in young children. Physical spaces designed for children must meet the need for social interaction as well as preserving the possibility of privacy. Persons on European squares act to acknowledge and confirm each other'spresence. And, if they are fortunate, children get a sense of the pleasure and some experience in being with, meeting and talking to each other Crowhurst Lennard S, Lennard $H$ [14]. Lack of attention to the different ways children (could) use their cities (public realm especially) can have dire consequences for the future of urban design in creation of livable cities. Cities urban public spaces need to be designed in such a way to support sociability and constructive exchange, not destructive behavior Lennard H, Lennard Crowhurst S [12].

Figure 3 As we mentioned above, the concept of third place, developed by Ray Oldenburg, is distinct from first and second places. A first place is the private space of home. Second places are where people spend significant time, often formally. These include schools, universities and workplaces. Common examples of third places in cities include community gardens, libraries, public swimming pools, cafes, men's sheds, farmers' markets and dog parks. There is growing understanding of the negative outcomes 
and costs associated with loneliness, especially with elderly generation. These include fractured communities, declining trust, stress, depression and disease. Clearly this is neither desirable nor sustainable. More than a century ago the sociologist George Simmel G, Wolff KH [15] observed how mobility disrupts social connection and creates isolation. The urban migrant, or a lonely senior citizen leaves behind her/his own social ties and often struggles to connect to the new community or lack of such. These challenges feel both the migrant, the elderly and their new neighbors around her/him. Third places can help by creating or enhancing a sense of community on a smaller, more human scale a relief from the overwhelming sensory experience of a large and unfamiliar city.

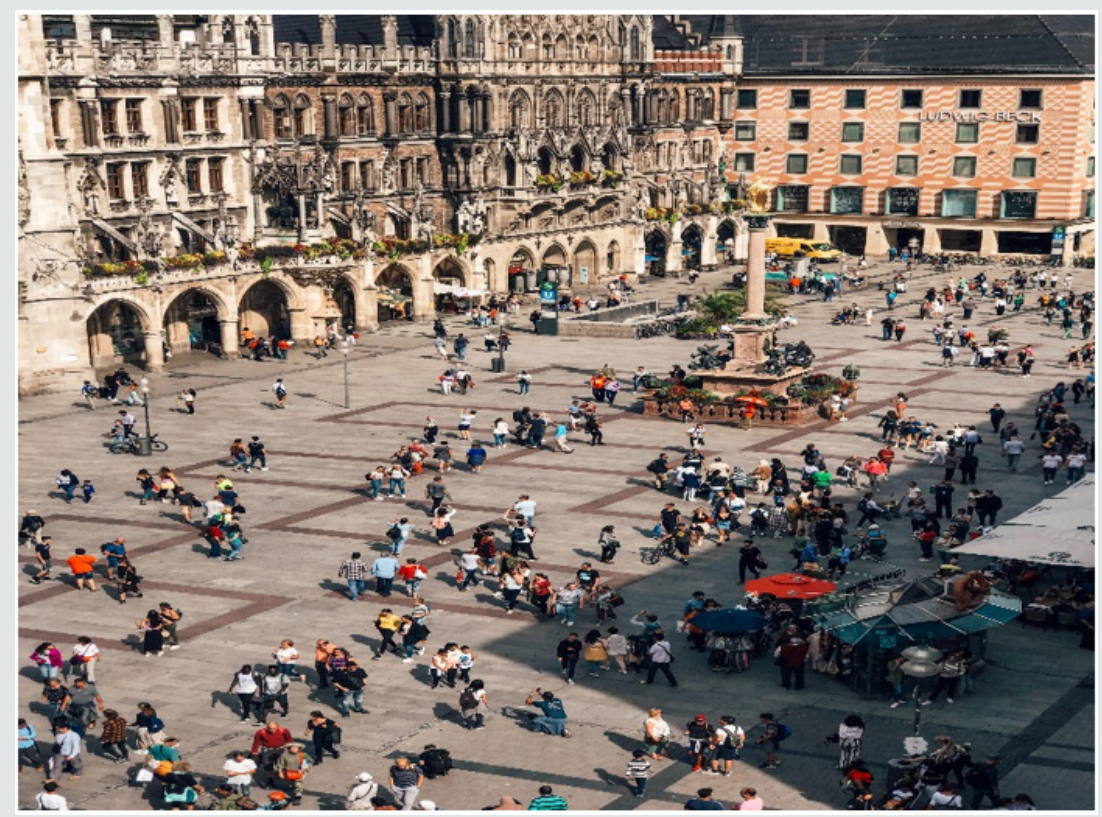

Figure 3: Marien Platz, Square in Munich Germany by Jan Kolario, Reproduced by Permission.

The village-like feeling of third places can reduce people's anxieties and make them more comfortable with trying a new social experience, therefore minimizing the urban loneliness. Loneliness has been associated with objective social isolation, depression, introversion, or poor social skills. However, studies have shown these characterizations are incorrect, and that loneliness is a unique condition in which an individual perceives himself or herself to be socially isolated even when among other people' while human longitudinal studies indicate that the 'harmful effects of loneliness are not attributable to some peculiarity of individuals who are lonely, instead they are due to the effects of loneliness on ordinary people' Miller G [16], Murthy V [17] and-the-loneliness epidemic and Masi CM, Chen HY, Hawkley LC, Cacioppo JT [18]. and Cacioppo JT, Cacioppo S, Capitanio JP, Cole SW [19].

\section{Implication for Planning and Urban Design Policy for Combatting (Urban) Loneliness through Urban form and Human Behavior approaches}

Implications for policy in urban planning and design for combating urban loneliness are extensive if all tenants of the place theory, i.e. Oldenburg's example of third place, can and could be included. As we mentioned before, community and society are on the classic linking elements. Community development programs recommend supporting elderly and intragenerational setting and links, small businesses geared toward the young and middle aged, children's suitable environment and third places for their peoplebased social benefits, might be the key. Some researchers suggest that pace-street based businesses that are considered "third places" by the users of those same "Main or High Streets" influence their immediate public space by paying more attention to and providing place-based urban design characteristics that help make good people places Mehta V, Bosson JK [20].

These and other findings have implications for urban design, community planning, city management and economic development policies. What we see from our research as emerging issues for policy and design implications and implementations, those with spatial and social value (physical and social sustainability efforts) are issues of natural accessibility and acceptable distances for elderly, proximity to destination of value and utility and mixed use for socialization and publicness and familiarity to spaces and place attachment in terms of sense of place and place recognition. An addendum to this, in the age of crime, fear and pandemics, an additional issue of gentle density and green spaces is a must.

Dykstra [21] uses the distinction between emotional and social loneliness in an attempt to unpack the complex nature of loneliness and its association with other psychological responses to company, community and society. "Emotional loneliness" encompasses feelings of desolation and insecurity that result from missing or losing an intimate attachment and so having no-one to 
turn to. In seeming contrast, "Social loneliness" is characterized by the perceived lack of a circle of friends and acquaintances who can provide a sense of belonging, companionship and community. When thinking about the role that urban planning and urban design or placemaking (for policy and implementation) has in addressing loneliness the obvious conclusion would be that the focus should be on social loneliness Dykstra PA [21]. Gotesky's [22] claims that there are 4 kinds of loneliness, that loneliness is a contemporary phenomenon, and that loneliness can be transcended. Gotesky distinguishes between physical aloneness, the spatial and/or temporal separation from others; loneliness, the feeling of being rejected by one's fellows or excluded from their activities and interests when one desires to be included and accepted; the state of feeling isolated, which derives from the rational recognition of conditions of existence which one does not know how to change; and solitude, a state of living or working alone which is free from the pain of loneliness or isolation Gotesky $\mathrm{R}$ [22]. Loneliness has always characterized the consciousness of man: It is a permanent condition that may be alleviated but not transcended, because each human ego is unavoidably confined to its own realm of monadic, opaque, and solipsistic consciousness. Mijuskovic B [23]. It is evident that the experience of loneliness is a very rich plethora and mix of a number of variances of emotional experiences Nisenbaum $\mathrm{S}[24]$.

Urban planning \& design have enormous potential to address issues like human loneliness and the health and wellbeing of citizens, in this case the ageing society. To realize this promise, it must be valued differently and formulated around contemporary social scientific understanding of human 'needs', not aesthetic architectural narratives. Eric Miller [25] Cities simply need to accept and adapt to multigenerational urban settings, ageing in place strategies, smart ageing and the combination of traditional and contemporary lifestyles and accessibility where the "senior city" or "geographies of age" generation of people cannot and must not be cut off from the rest of society, with age becoming a new form of segregation, one which ultimately provides the ground for emerging and growing urban loneliness.

On the contrary cities and planners and urban designers need to accept that they - the ageing society and the new reality reflects a desire for an active, experience-filled lifestyle. In this fashion, three interrelated aspects of ageing must be considered in creating policy responses for ageing societies: i) individual ageing; ii) population ageing; iii) the new equilibrium of societies that have undergone the different stages of an ageing trend Ageing Societies: A Comparative Introduction, McGraw-Hill. Finally, policy makers need to nurture, manage, retain and support the third places of Oldenburgian type that exist in neighborhoods; if they don't, they need to be regenerated or created. All should realize the social value of being recognized as a third place and follow business models that help them become third places Oldenburg $\mathrm{R}$
[26]. Policy makers need to be sensitive to both the existing and the new third places in neighborhoods and value them not only for their social attributes but also for their contribution to the design quality of the public spaces in which they exist Mehta V, Bosson JK [10]. There is ultimately a need to develop an adaptable, resilient and inclusive place strategy to address urban loneliness, sort of a proactive placemaking approach that will have nexus in the need for prosocial places; ones combating lonely cities-empty spaces and isolated places.

Finally, there is a need to take a few steps back and position the whole issue of public spaces and loneliness in a larger scheme, an almost metaphysical conceptual contour. There are multiple and even limitless ways of understanding, approaching and analyzing the subject of (urban) loneliness in contemporary culture and society, i.e. in our cities. Loneliness is largely a social phenomenon and a social form Johansson, $\mathrm{T}$ and Andreasson T [27]. (Urban) Loneliness, product of partly (urban or 'agorian') social (and even physical) isolation and retreat and partly our own subjective (metaphysical, subconscious, conscious and synchronicity) interpretation of our lives, can become a public health problem in our cities. Why? Simply because it degrades the lives of the public, bring down the quality and joy of being, makes our lives shorter and unhealthier; our bodies and motoric prone to sickness and disease, our minds vulnerable to anxiety, stress, isolation, alienation, depression and other mental illness and daytime/ nighttime problems. But as with most ailments that manifest in our individual bodies, loneliness is also a failure of our environments, and the powers who have created or neglected them Ankita Rao [28]. The (urban) loneliness that city dwellers are experiencing today, are obviously not imbedded and rooted in any one (single) phenomenon or reason, though we easily slip into believes of blaming the "modern" causes of this: breakdown of the traditional nucleus family unit, disappearance of porches in front of our houses, urban sprawl, bowling alone, dominance of the car, the mindless network society and its "evil" city of bits: scroll-click-scroll of our phones and tablets, or the endless stress always-connected-onjobs-online feeling that follow us home through emails, SMSs texts, Whatsups, Instagram's, Facebooks, Twitters and other messages. What really is needed is a deeper understanding of the triad of complexity: space, place and time. If we do not understand that we will never understand (urban) loneliness and thereby never be able to intervene in proper way in urban planning \& design. We have a pretty good understanding what good public realms are and what good urban design is and the position of loneliness within; but without a thorough understanding of "time" as the main pinnacle of the cubus or triangle of concepts and categories, we will never arrive anywhere.

Marc Wittmann (2016) gives us a fascinating inquiry into how our subjective experience of time's passage shapes everything from our emotional memory to our sense of self. This is also extremely 
important for our cities and public realms and us within them. "Consciousness is tied to corporeality and temporality; I experience myself as existing with a body over time...If one has no time, one has also lost oneself. Distracted by the obligations of everyday activities, we are no longer aware of ourselves... Everything is done all at once, faster and faster, yet no personal balance or meaning can be found. This implies the loss of contact with one's own self. We also no longer feel "at home" with ourselves and find it difficult to persist in any given activity because we are available at every moment", Marc Wittmann [29].

"If we had deliberately aimed to make cities that create loneliness, we could hardly have been more successful," said Suzanne Lennard, an architect and the director of the International Making Cities Livable movement and author of some of the leading works on public spaces. Lennard said "we have lost some of our cities' most essential components, like the plazas and piazzas that once formed the center, allowing for people to naturally bump into each other, or interact while shopping, eating, and walking. Which is why urban planners and designers have started to look at the pathways, gardens, and building façades that have become staples of the urban milieu. In other words, they are examining many of the features we pass by every day without so much as knowing how such things influence our psyche". Lennard S [30]. At the end of the day, understanding the underlying problems that create and contribute to urban loneliness, understanding the complexity of space, place and time, and accepting the reality of everyday urbanism, i.e. contemporary urbanism in general will be sine qua non for moving beyond merely theorizing and analyzing the problems; but instead through research and practice outputs shows that an alternative, for a less lonely 8urban) future is indeed possible. Without claiming to solve (urban) loneliness, urban planning and urban design can be an important tool in response to it (Figure 4).

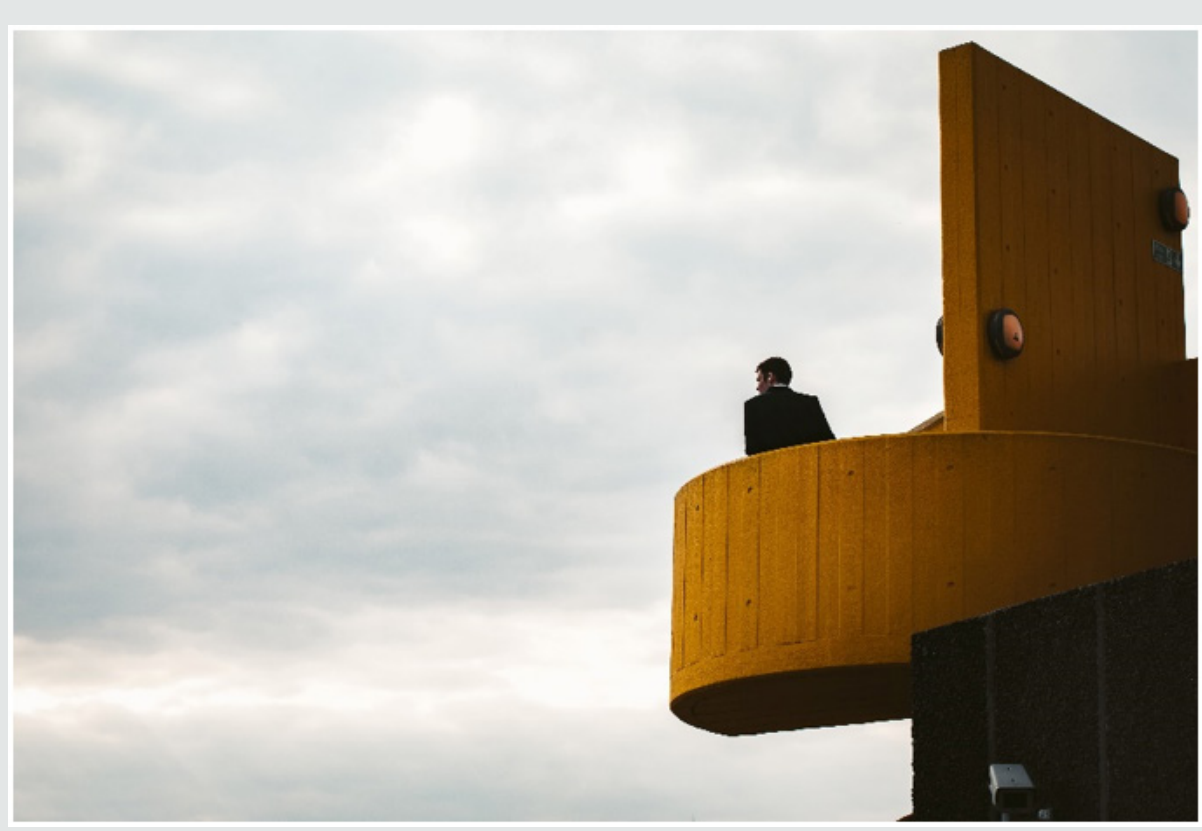

Figure 4: Urban Loneliness, South Bank, London, United Kingdom by Mark Hayward. Reproduced by Permission.

\section{References}

1. Banerjee Tridib (2007) The Future of Public Space: Beyond Invented Streets and Reinvented Places. Journal of the American Planning Association p: 9-24.

2. Oldenburg Ray (1999) The Great Good Place: cafés, Coffee Shops, Bookstores, Bars, Hair Salons, and Other Hangouts at the Heart of a Community. New York: Marlowe, UK.

3. Oldenburg R (1999) The Great Good Place. New York: Marlowe \& Company, UK

4. Soja Edward W (1996) Third space: journeys to Los Angeles and other real and imagined places. Cambridge, Mass: Blackwell pp:250-348.

5. Lefebvre H (1974) The Production of Space. Oxford: Blackwell.

6. Harvey D (2012) Rebel Cities: From the Right to the City to the Urban Revolution. New York: Verso Books.

7. Hillery G (1968) Communal Organizations-A Study of Local Societies. Chicago: University of Chicago Press.
8. Putnam R, Lewis F (2003) Better Together: Restoring the American Community. New York: Simon \& Schuster, New York.

9. Lennard Crowhurst S, Lennard H (2004) Principles of True Urbanism, International Making Cities Livable, IMCK, Gondolier Press: Carmel.

10. Oldenburg R (2002) Celebrating the Third Place: Inspiring Stories About the "Great Good Places" at the Heart of Our Communities. New York: Marlowe \& Company.

11. Putnam RD (2000) Bowling Alone: The collapse and revival of American community. New York: Simon and Schuster.

12. Lennard H (2000) The forgotten child: Cities for the well-being of children. Gondolier Press, Carmel, Crowhurst Lennard S, Lennard H (Eds.), Genius of the European Town Square. Carmel: Gondolier Press.

13. Gehl J (1996) Life Between Buildings-Using Public Space. Copenhagen: Arkitektens Forlag.

14. Crowhurst Lennard S, Lennard H (2005) (forthcoming) Genius of the European Town Square. Carmel: Gondolier Press. 
15. Simmel G, Wolff KH (1964) The Sociology of Georg Simmel. The Free Press: New York.

16. Miller G (2011) Social neuroscience. Why loneliness is hazardous to your health. Science 331:138-140.

17. Murthy V (2017) Work and the loneliness epidemic. Harvard Business Review (Brighton).

18. Masi CM, Chen HY, Hawkley LC, Cacioppo JT (2011) A meta-analysis of interventions to reduce. loneliness. Pers Soc Psychol Rev 15: 219-266.

19. Cacioppo JT, Cacioppo S, Capitanio JP, Cole SW (2015) The neuroendocrinology of social isolation. Annu Rev of Psychol 66: 733767.

20. Mehta V, Bosson JK (2010) Third Places and the Social Life of Streets. Environment and Behavior 42(6): 779-805.

21. Dykstra PA (2009) Older adult loneliness: myths and realities Eur J Ageing 6:91-100.

22. Gotesky R (1965) Aloneness, loneliness, isolation, solitude. International Journal of Medicine. An invitation to phenomenology. Chicago: Quadrangle.

23. Mijuskovic B (1977) Types of loneliness. Psychology: A Journal of Human Behavior 14(3): 24-29.

24. Nisenbaum S (1987) Ways of Being Alone in the World. American Behavioral Scientist 27(6): 785-800.

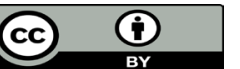

This work is licensed under Creative

Commons Attribution 4.0 License

To Submit Your Article Click Here:

Submit Article
25. Eric Miller (2017) From lonely cities to prosocial places How evidenceinformed urban design can reduce the experience of loneliness" by Rhiannon Corcoran, Graham Marshall, Chapter 11 IN "Narratives of Loneliness", Multidisciplinary Perspectives from the $21^{\text {st }}$ Century Edited by Olivia Sagan, Routledge; London, England.

26. Oldenburg R (2002) The great good place: Cafes, coffee shops, bookstores, bars, hair salons, and other hangouts at the heart of a community. New York: Marlowe.

27. Johansson T, Andreasson $T$ (2017) The Web of Loneliness: A Netnographic Study of Narratives of Being Alone in an Online Context. MDPI Social Science Journal Soc Sci 6(101): 1-15.

28. Ankita Rao (2018) Our Cities are Designed for Loneliness: Our built environment is not working in our favor and urban planners want to change that. VICE Magazine.

29. Marc Wittmann (2017) Felt Time: The Psychology of How We Perceive Time. Published by: The MIT Press, Cambridge, UK.

30. Lennard S (1984) Public Life in Urban Places: Social and Architectural Characteristics Conducive to Public Life in European Cities 1984, Gondolier Press: Carmel; The Venetian Campo: Ideal setting for social life and community (Eye on Venice Book 24) 2015, Venice: Corte del Fontego Editore and (with H. Lennard) Genius of the European Square, 2008, Gondolier Press: Carmel.

\begin{tabular}{|l|l|}
\hline SJPBS & $\begin{array}{c}\text { Scholarly Journal of Psychology } \\
\text { and Behavioral Sciences }\end{array}$ \\
Assets of Publishing with us
\end{tabular}

